\title{
Música, memoria e identidad en Un silencio de corchea de Daniel Moyano
}

\author{
Irene Noemí LÓPEZ \\ Universidad Nacional de Salta-INSOC-CONICET
}

\section{RESUMEN}

Daniel Moyano escribió Un silencio de corchea durante su exilio en España. Esta situación particular genera una escritura basada en los recuerdos de un espacio y un tiempo lejanos, en que la música se transforma en el paradigma de una forma de entender el universo.

El libro se estructura en dos partes: Del tiempo y De la música pero que, según palabras del mismo Moyano, en el fondo tratan de lo mismo. La segunda parte, con un notorio tono autobiográfico, constituye una serie de relatos de un narrador que recuerda sus experiencias como intérprete musical en pueblos del interior argentino.

Este artículo analiza en dos relatos, "María Violín” y "Un silencio de corchea", la particular relación que se establece entre música, memoria y construcción de identidad.

Palabras clave: Música, memoria, identidad.

Music, memory and identity in Un silencio de corchea by Daniel Moyano

\begin{abstract}
Daniel Moyano wrote Un silencio de corchea while he was exiled in Spain. This particular situation generates a writing based on the memories of a distant space and time, in which music becomes in the paradigm of a way of understanding the universe. The book is structured in two parts: Del tiempo and De la música but, according to Moyano's words, both refer basically to the same thing. The second part, with an autobiographical tone, constitutes a series of stories about a narrator who remembers his experiences as a musical performer in small villages of Argentina.

In this article we analyze in two stories, "Maria Violín" and "Un silencio de corchea", the special relationship among music, memory and identity construction.
\end{abstract}

Key words: Music, Memory, Identity.

SUMARIO: 1. Introducción. 2. Del tiempo, la música y la memoria. 3. El amor, la muerte y la música. 4. Una subjetividad del extrañamiento y del desgarro.

\section{Introducción}

Las relaciones entre música y literatura adquieren un matiz especial en la escritura de Daniel Moyano. Toda la producción literaria del escritor argentino está sig- 
nada por la música, en tanto ésta la configura semántica y estructuralmente. Nos interesa por ello analizar Un silencio de corchea desde la particular relación que allí se establece entre música, memoria y construcción de identidad.

Los relatos de Un silencio de corchea fueron escritos por Daniel Moyano entre 1980 y 1990 durante su exilio en Madrid. Esta situación particular genera una escritura basada en los recuerdos de un espacio y un tiempo lejanos y distintos a los del momento de la enunciación, en que la música se transforma en el paradigma de una forma de entender el universo y de experimentar de una manera especial la percepción del tiempo.

El libro se estructura en dos partes: Del tiempo y De la música pero que, según palabras del mismo Moyano, en el fondo tratan de lo mismo. La segunda parte, con un notorio tono autobiográfico, constituye una serie de relatos de un narrador que recuerda sus experiencias como intérprete musical en pueblos del interior argentino. De esta manera, la actuación de Moyano como violista en un cuarteto de cuerdas del noroeste argentino entre 1960 y 1976 es la que genera esta escritura que se convierte en una forma de activar la memoria y los recuerdos de un pasado lejano.

Por ello, en los relatos que componen este libro la música es el eje sobre el cual se construye la subjetividad y que permite el ejercicio de la memoria. Un ejercicio que se torna al mismo tiempo doloroso y necesario por los acontecimientos a narrar, comprendidos en el momento previo a la violencia del terrorismo de Estado y a la violencia del exilio. Así, se trata de una subjetividad construida en y por la música; y construida también a partir de la recuperación -mediante la escritura- de una memoria compuesta por sonidos dispersos que requieren de una organización temporal que las rescate del caos para convertirlas nuevamente en cosmos y armonía.

La experiencia musical, por lo tanto, no sólo engendra la escritura sino que, al mismo tiempo, constituye la clave para desentrañar los sentidos que adquieren los recuerdos allí plasmados, transformándose en símbolo y metáfora. Centraremos nuestro análisis en dos relatos, "María Violín" y "Un silencio de corchea" con el objetivo de mostrar como operan dichas metáforas en relación con el funcionamiento de la memoria y la emergencia de los conflictos en torno a la construcción de la identidad latentes en esta escritura realizada desde el exilio.

\section{I- Del tiempo, la música y la memoria}

El constante juego entre lo que se recuerda y valora desde ese presente de la escritura va dando cuenta de una forma de interpretar no sólo el pasado personal sino también el colectivo. Sin pretensiones de convertirse en cronista o historiador, el

${ }^{1}$ Todas las citas se harán por esta edición: Un silencio de corchea. Oviedo: KRK Ediciones, 1999. 
narrador opta por dar vía libre a la imaginación y recurre constantemente a metáforas musicales para explicar su particular concepción del tiempo y de la memoria e intentar construir desde allí su lugar de pertenencia.

El paratexto condensa esa concepción del tiempo metaforizada a través de la música: "un silencio de corchea" es un momento breve, apenas la mitad de un pulso, momento expectante que antecede a un desandar los hilos del tiempo y que en sí mismo contiene a la eternidad. Todo es posible en ese fragmento. Expresa una paradoja entre el tiempo medido matemáticamente (el valor de la corchea) y el sentido de la percepción: la expectativa de su llegada, la eternidad del instante, su futuro significado. El libro abre y cierra con un silencio de corchea, apenas un suspiro que marca el impulso para comenzar o bien la posibilidad del final abierto. Ese breve lapso de tiempo medido cronométricamente es el aliento necesario para comenzar a desentrañar los vericuetos de la memoria y permitir que la imaginación y los recuerdos fluyan.

Se reitera en todos los relatos una misma idea: los recuerdos flotan inconexos en un tiempo laxo y sin medidas; el trabajo de la memoria, siguiendo una lógica propia, podríamos decir "creadora", selecciona, mezcla, inventa, une hechos fortuitos, convierte en causal aquello que aparentemente es casual. Así es como sintetiza el narrador este procedimiento:

El tiempo transcurrido le permite a uno mover esos elementos de otra manera. Despojados de su contemporaneidad, flotan en el aire como astronautas fuera de la cápsula; Allí don Manuel [de Falla] y Ernesto [Che Guevara] y mi tía se rozan en sus giros, pueden tener todos esos encuentros que la cronología o el azar (o el tiempo mismo, que mientras permanece en el presente es tan pobre y limitado), les negó en su momento. ("Los incorpóreos", 24)

A partir de este fragmento podemos inferir esa percepción del tiempo y cómo opera la memoria en esta escritura. Quien opera desde el aquí y el ahora de la escritura abarca, en relación a los hechos que recuerda y pretende relatar una percepción global del pasado, el presente y el futuro. Desde allí también opone, por un lado, el devenir y su organización a través de cronologías, de sucesos ordenados según una lógica causal; $\mathrm{y}$, por otro, un coexistir de todos los tiempos y sucesos sin orden aparente. La puesta en relato de esos sucesos desordenados e inconexos supone una organización que, como sostiene Paul Ricoeur (1984), convierte a la escritura en una forma de conferir sentido a la existencia humana.

El particular sentimiento de la temporalidad que se experimenta a través de la música tal vez se deba al devenir de su ejecución, al establecimiento de una suerte de eternidad a través de sus formas, a la permanencia en ellas de signos del pasado que encierran en sí mismos la potencialidad de futuras ejecuciones. Por ello en la nota introductoria a estos relatos, Daniel Moyano concluye que las dos secciones "Del tiempo" y "De la música"- "en el fondo tratan de lo mismo". 


\section{II- El amor, la muerte y la música}

"María Violín" se abre con dos epígrafes; el primero de ellos remite a la soledad y a la falta de amor que experimentan los exiliados y que conduce, en un primer momento, a la muerte del deseo y, luego, directamente a la muerte física. El segundo es un fragmento extraído de los apuntes del conservatorio musical que explica cómo Pitágoras, a través de un monocordio, estableció las primeras leyes de la armonía y de la acústica musical. Ambos constituyen la matriz de sentido de este relato.

El protagonista, Manuel "el suramericano", como forma de conjurar la soledad y vencer el frio del invierno madrileño, recurre a la música y toca la quena trasladando así, imaginariamente, su lugar de origen a este otro espacio que se experimenta hostil. Se produce así una coexistencia conflictiva entre prácticas, costumbres, sabores, elementos que pertenecen al "allá" americano y aquellos otros del "acá" madrileño. Los pensamientos en torno a esta situación constituyen una manifestación más de la identidad fracturada de un yo que se siente extraño y hasta ajeno de sí mismo, un desdoblamiento que se expresa en frases como ésta: "el otro que era cuando se paseaba como exiliado de sí mismo por un Madrid fantasma o humo" (34) o a través de monólogos interiores:

Al fin y al cabo te lo estas pasando bien en tu bohardilla de hombre solo, con tu quena, tu mate, los discos de la Negra Sosa y tu trabajo de fotógrafo, le gustaba decirse a sí mismo ahora que era otro. (34)

El intertexto musical está presente desde el comienzo: su ventana y la de un departamento del edificio de enfrente están unidas por un tendedero, una cuerda tensa que une los dos extremos, en forma similar a la del monocordio de Pitágoras. En ese tendedero se va a anunciar la sorpresiva aparición de una mujer, también extranjera, que reaviva la pasión erótica en Manuel. Primero es el indicio de su presencia: una prenda íntima en el centro justo de la cuerda tensa del tendedero (es decir, el intervalo de octava). "En función de monocordio una prenda íntima de tela transparente apareció una mañana tendida a secar en el centro de la cuerda." (35)

A partir de ese momento se instala una lucha entre el amor (deseo) y la muerte en la cual el "Romance del enamorado y la muerte" oficia de hipotexto. La muerte, esa "señora muy blanca, muy más que la nieve fría" acecha al protagonista pero, a diferencia del romance, en este relato vence el amor y Manuel puede concretar la relación amorosa con la habitante del departamento al que lo une la cuerda tensa del tendedero. El Romance anónimo cumple una función estructurante: sus versos se intercalan en momentos significativos de la trama; la historia de Manuel y la mujer extranjera resulta una versión actualizada de aquella otra del enamorado que pide a su amada -la niña de largas trenzas- asilo porque la muerte lo está buscando. Las diferencias o variaciones al mismo tienen que ver con la procedencia de Manuel -es sudamericano- y con su condición de exiliado. 
La función del "Romance del enamorado y la muerte" en este relato permite realizar analogías estructurales con diversos procedimientos compositivos musicales. Una aclaración es pertinente: ya que se trata de dos lenguajes muy diferentes, la traducción de uno a otro nunca es literal y por ello, la utilización de recursos musicales en este relato en particular, contribuye a intensificar la polisemia y habilita múltiples lecturas. Por un lado, como vimos, el hipotexto del romance puede oficiar a la manera de un tema y variaciones. Por otro, la presencia de otros dos intertextos que remiten simultáneamente a la muerte y al exilio, uno de ellos el verso de César Vallejo, parodiado, "Moriré en París con aguacero" y, el otro, "Vendrá la muerte y tendrá tus ojos" de Cesare Pavese ${ }^{2}$, actúan a la manera de leiv-motivs. Finalmente, podemos interpretar que los tres intertextos literarios señalados junto al intertexto de la concepción pitagórica de la música funcionan de modo similar a la participación de los músicos que intervienen en un cuarteto de cuerdas: dialogando, confrontando, reforzando una voz, etc. Esta última posibilidad es también inducida por el mismo Daniel Moyano, cuando comenta que comprendió al mismo tiempo la estructura literaria y la musical a través de la partitura de un cuarteto para cuerdas de Brahms, una estructura que se genera a partir del diálogo en su forma básica de pregunta-respuesta. Así, el acto de comprender el comportamiento y funciones de los instrumentos en un cuarteto le permitió simultáneamente a Daniel Moyano organizar la escritura literaria:

No sé escribir novelas [...] Yo sabía qué quería decir pero no encontraba una estructura. Estábamos aquí en La Rioja con los compañeros de la orquestita, estudiando un cuarteto de Brahms que yo había comprado en Londres. Pero no podíamos. No somos virtuosos y aquello era para virtuosos. Me traje la partitura a casa, empecé a leerla, y de golpe, ¡qué maravilla! [...] El chelo hace tara-ra-ra. Los demás instrumentos le van respondiendo, porque lo que el chelo hizo fue una pregunta. (Gilio, 1986: 72)

Es igualmente posible leer la lucha entre el amor y la muerte como dos temas contrapuestos, que emulan la lucha temática de la forma sonata. Como señalamos más arriba, el tema de la muerte se construye con los versos de Cesare Pavese "Vendrá la muerte y tendrá tus ojos"-y de César Vallejo -"Moriré en París con aguacero" que actúan de leiv-motivs e intercalando fragmentos del "Romance del enamorado y la muerte". El tema del amor, por su parte, se compone a partir de los

${ }^{2}$ Se establece un contrapunto entre ambos escritores. Por un lado, Manuel se dice a sí mismo: "Cuidado con lo de Pavese, es demasiado drástico y muy poco latinoamericano" (34); por otro, irónicamente recuerda: "El resto de tu vida, cabezón. Te lo dije cuando te subiste al barco. Y nada de me moriré en Madrid con aguacero, Vallejo es de otro tiempo y otra sensibilidad" (34). 
intertextos de la teoría pitagórica sobre la música y la armonía universal -el monocordio, los intervalos musicales, y la armonía cósmica, espiritual y física.

El amor (la prenda en función de monocordio) y la muerte se anuncian simultáneamente. El exilio y la falta de amor se erigen así como una forma más de muerte. Realizando otra analogía musical, puede concebirse que el lugar desde el cual se construye la enunciación, es decir la situación de exilio, oficia a modo de tonalidad desde la cual se organiza el discurso, es decir desde la cual, en el discurso musical se estructuran tanto la melodía como la armonía.

La primera forma de comunicación entre Manuel y su amada se concreta a través de los sonidos. Ésa es su primera forma de contacto: Manuel se presenta ante ella con el sonido de la quena, y ella, por su parte, con una flauta. No casualmente, emiten los sonidos que corresponden a un acorde mayor; sonidos que se forman por la división de la cuerda, aquellos mediante los cuales Pitágoras estableció las relaciones numéricas que expresan la distancia entre un sonido y otro y que hoy conocemos como intervalos. La quena de Manuel emite un mi, la flauta dulce de la mujer un sol y la quena responde con un do: acorde perfecto mayor en primera inversión.

El epígrafe que inicia el relato y remite a los descubrimientos de Pitágoras cobra así un sentido especial. Pone en juego una particular concepción musical que organiza el sentido - tanto del universo como de este texto- que se remonta a la antigüedad griega y se continúa a través del medioevo cristiano y la modernidad. En tal concepción de la música el concepto de armonía es fundamental. En la concepción pitagórica la armonía expresa la unión de contrarios, es sinónimo de "equilibrio" y debe manifestarse tanto en el interior del hombre como en el Estado, ambos en concordancia con el universo. La armonía se manifiesta en el universo contraponiendo: caos/cosmos como un equilibrio y una unión de contrarios. Este concepto también se relaciona con las matemáticas: decía Aristóteles que para los pitagóricos, "todo el cielo era una escala musical y un número" (cfr. Rowell, 1996: 50).

Esta concepción es continuada en el medievo a través de la distinción entre música "speculativa" y "práctica". Boecio propone una clasificación tripartita de la música: mundana, la música de las esferas, no oída por los hombres; la música humana, la armonía que existe dentro del hombre entre alma y cuerpo; y la música instrumentalis, la música hecha por el hombre, imitación imperfecta de las músicas superiores (Cfr. Rowell, 1996: 52). Se trata de una distinción importante que también opera en la escritura de Daniel Moyano: la idea de que existe una música de las esferas, una armonía cósmica inaudible para los oídos humanos.

Daniel Moyano expresa explícitamente esta concepción en una entrevista realizada por María Esther Gilio (1986). Para definir esta concepción de la música cita a Kepler, quien sostenía que

...la tierra al desplazarse producía un sonido, una música en el espacio. Pero que esa música no se la podía oír con los oídos, sino con el intelecto. Y que esta mú- 
sica nuestra es sólo una interpretación de esa otra que no podemos oír. Sólo Dios puede oírla, decía. (1986: 78)

Los sentidos desplegados por el concepto de armonía constituyen por lo tanto la clave de lectura para estos textos. El concepto se despliega, al menos, en tres dimensiones: la armonía como equilibrio cósmico que produce una música inaudible; la armonía en tanto las proporciones matemáticas que se expresan en los intervalos; la idea de equilibrio que en el texto se simboliza en el tendedero que oficia no sólo como la cuerda que en sus subdivisiones produce intervalos sino también aquella que exige la destreza del equilibrista (Manuel debe cruzar esa cuerda para obtener lo que desea).

Tanto el equilibrio como la armonía están alterados en una situación de exilio. En "María Violín" la forma de reponer o reconstruir ese equilibrio es a través del amor: la unión física de dos cuerpos que vibran y la unión de contrarios, de dos sujetos, conciencias y almas que se funden en una. Así, la unión amorosa también se explica en términos musicales.

Lo que esta escritura incorpora y repone en esta concepción de lo musical es la dimensión corporal. De esa manera dota de erotismo a esta concepción cuyos derroteros siguieron los rumbos de lo científico o de lo místico-religioso. Al igual que los instrumentos que emiten sonidos, el narrador explicita que "los cuerpos han sido pensados para la música, son instrumentos vivos." (38) y, parafreseando aquellos apuntes de acústica del conservatorio, se explaya:

Para producir un sonido es necesario que un cuerpo elástico entre en vibración, que el equilibrio molecular se rompa, y para eso están los variados golpes de arco, las fricciones debidamente dosificadas en su justo ritmo. (43)

Unidos por la cuerda del tendedero, con la mariposa-monocordio a medio escarchar en el centro, la mujer nórdica y Manuel son el instrumento y el ejecutante, lo único que falta es producir la música. Con mi quena, dice Manuel, te hago vibrar toda en libertad. Tu mariposa íntima divide la cuerda en dos segmentos exactamente iguales, y el sonido que produce es la octava del sonido de tu cuerpo. $\mathrm{Si}$ corremos la mariposa hacia los dos tercios de la cuerda y hacia tu ventana, tenemos un intervalo de quinta, y avanzando un poco más el de cuarta, consonacias perfectas, gracias Pitágoras, estoy casi en sus brazos. (44)

El final de la historia recuerda a los relatos míticos. La lucha entre el amor y la muerte termina finalmente con el triunfo del deseo: Manuel y la mujer extranjera (nórdica o eslava) se transforman en María Violín y Manuel Arco, los dos elementos necesarios en un instrumento de cuerda para producir sonido. Esta metamorfosis, al mismo tiempo que los salva de la muerte, convierte al violín en un símbolo del amor entre un hombre y una mujer: 
María Violín y Manuel Arco junto al fuego rompiendo el equilibrio molecular, que para eso están los impulsos, las fricciones de tiempo justo. (47)

En "Un silencio de corchea" encontramos también esta concepción de la armonía universal, del orden cósmico y su música. El relato reconstruye una anécdota trivial, pero que desde esta perspectiva de lo musical, y teniendo en cuenta sus condiciones de producción, adquiere múltiples sentidos. Una inesperada invasión de cascarudos en medio de un concierto en un pueblo de La Rioja ocasiona la muerte de uno de aquellos insectos que, inoportunamente, se había prendido de la oreja de la pianista. El silencio de corchea en medio de esa obra deja de ser meramente un signo que cumple una función en la estructura musical del Adagio y Rondó Concertante en Fa Mayor de Schubert para convertirse en un breve momento en el cual

...durante cientos de años, estuvo escondida y al acecho un arma asesina ante la cual, en un encuentro que pareció calculado como si se tratase de una cita, encontró la muerte una forma viviente de este contradictorio planeta que compartimos, entre otros, con los demás animales y la música. (149)

Desde la concepción de la música como armonía universal, este hecho fortuito implica un desequilibrio. Por ello el relato se desarrolla siguiendo los conflictos de conciencia que ocasionó en el narrador tal situación porque, coherente con tales convicciones:

... los insectos eran también naturaleza, y a su modo, música. (158)

Por ello, el narrador considera a esta música universal como parte de lo natural; es aquella que todos como seres vivos ejecutamos:

La música debía su tremenda fuerza al hecho de ser naturaleza, no invención del hombre. Existió antes que él, y la amábamos porque era la piel que nos permitía acariciar el mundo; porque era una actitud de la naturaleza para que pudiéramos sentirla en el tacto, modelarla como arcilla, mezclarnos con ella millones y millones de veces y escuchar, en su pulso, el del universo, lejos de su ferocidad inevitable. (158)

El relato construye acabadamente la idea de que esa música de las esferas inaudible se distingue de la música terrenal realizada por los hombres valiéndose de instrumentos y voces. Ésta última sería una forma inventada por los hombres para intentar recuperar un pasado (paraíso) perdido. Para el narrador, al igual que los hombres, estos bichos se sienten irremediablemente atraídos por esos arcanos que la música representa: 
La idea de que los insectos eran notas musicales perdidas se fijó en mi mente. [...] se posaban sobre las partituras, que eran sus verdaderas luces lejanas, ya enigmas definitivos para ellos, aspectos físicos bajo los cuales estaba oculto para siempre el bien perdido. La música, de la que por naturaleza alguna vez formaron parte, se había evadido hacia las formas; pero ellos, que poseían la memoria cósmica, conservaban ese lejano hecho como un riguroso presente [...] Y sin embargo iba a matarlo. (159)

En la música de las esferas, del universo, el hombre vibra en consonancia con la naturaleza de la que forma parte junto con los demás seres vivos. Por ese motivo a este músico le cuesta matar al bicho, porque ese asesinato implica la alteración de un equilibrio, produce una disonancia en el orden universal, en la armonía universal:

Matar. Una palabra que se dice fácil. Pero para mí, lector de T. S. Eliot, significaba atreverme a perturbar el universo. Toda vida forma parte de la trama invisible. (157)

Entran en pugna así dos argumentos contrarios. Por un lado, el del equilibrio universal y la defensa de la vida contra toda forma de poder y de violencia. Por otro, los bichos en las partituras, en los instrumentos y en los cuerpos de los músicos se textualizan como amenaza, como una "invasión", como "parásitos", como la presencia molesta y perturbadora de una turba de seres

...como salidos a pasear en coche, negros, feísimos, contrahechos, de alas caídas unos, de patas medio quebradas otros, moviendo nerviosamente las antenas. (155).

Es imposible obviar las marcas en esta escritura del momento socio-histórico al que este relato remite y las heridas desde el cual se reconstruye. El texto, a través de una anécdota trivial, construye paulatinamente un clima de violencia, antesala del momento en el que Daniel Moyano, y muchos otros, debieron partir al exilio. En principio, esta inesperada presencia tiene un matiz irónico (humor):

Menos mal que sabíamos la obra de memoria, porque si hubiéramos tenido que atenernos a la lectura, los valores rítmicos estaban alteradísimos, en razón de que había bichos instalados en las negras, con cuatro patas atravesadas en la plica de la figura, que a modo de corchetes las convertían en fusas, y así, claro, hubiera resultado cualquier cosa, a lo mejor por culpa de o gracias a los bichos acabábamos tocando música bailable cuartetera y la gente por fín nos aplaudía, porque era eso lo que estaban esperando desde temprano. (154) 
A través de ese matiz irónico el narrador condena el ejercicio de un poder represivo y violento y se apropia, paródicamente, del lenguaje utilizado por los militares en Argentina para justificar la represión:

...lo verdaderamente fuerte era su significado, su parafernalia, su intención terrorista (deduje). (156)

La violencia también encuentra su metáfora en un silencio de corchea que permite el asesinato de aquel molesto bicho en la oreje de la pianista. El narrador músico utiliza ese silencio y el arco del violín para llevar a cabo su tarea ${ }^{3}$. Una tarea que le resulta no sólo molesta sino cuya decisión conduce a toda una serie de reflexiones filosóficas y morales. Por ello, decide que

Cometería el crimen a espaldas de la música, valiéndome de las sombras de un silencio de corchea. (158)

Progresivamente, se van configurando una serie de analogías entre la situación de los músicos que brindan el concierto y aquellos inoportunos insectos. En especial por la conciencia que tienen los músicos de estar en un lugar equivocado, en un lugar en el cual molestan y perturban, corriendo el riesgo de ser exterminados. La escritura genera así una clara analogía entre la situación de los bichos (inesperados, y molestos, visitantes en el concierto) y la de los músicos, también inesperados en el pueblo en el que van a tocar. El intendente, al recibirlos, les pregunta "¿Otra vez ustedes por aquí?" y continúa:

...el año pasado vinieron para esta misma fecha, ¿no?, y mientras esto dice, con mirada oblicua nos muestra sólo la parte blanca de sus ojos, a todas luces un reproche. [...] pero traten de ser breves por favor, no toquen todo el programa... (150)

El narrador, a través de sus disquisiciones filosóficas, sugiere que ambos -bichos y músicos- vuelven al mismo lugar guiados por un luz lejana que los atrae sin alcanzar a precisar el por qué ni el para qué de sus acciones. Desde la perspectiva que otorga el tiempo transcurrido, surge una posible explicación: la necesidad de la escritura para dar forma y sentido a esos elementos inconexos que flotan en el espacio sin tiempo de la memoria. Dice el narrador:

Incluso yo, intentando contar desde ahora esta historia que sucedió hace tiempo, lo hago porque descubro a lo lejos, como los bichos, esas luces lejanas de la memoria y me lanzo a ellas por necesidad impostergable. (159)

\footnotetext{
${ }^{3}$ El instrumento como arma mortal también se textualiza en El trino del diablo.
} 
De esta manera, la reconstrucción de la memoria y de la identidad se explica desde una necesidad que a su vez se vincula con la concepción del universo en términos musicales. La escritura literaria es como la partitura musical: ordena, organi$\mathrm{za}$, fija, construye un sentido, otorga sentido a una existencia. Pero ambas son formas que pertenecen al orden de lo inventado, de lo no-natural, un lugar seguro y de resguardo que atesora, como un secreto profundo, su origen cósmico. Entonces la música, la terrenal o instrumentalis según la clasificación de Boecio, se convierte en el lugar de la supervivencia:

Prefiero las formas inventadas que nos aíslan del volcán; la escritura a la viva voz; las figuras musicales, a los sonidos; la imaginación, a la realidad. Uno se salva de los delirios de la naturaleza por las formas. (157)

La muerte del bicho provoca, entre otras cosas, que el narrador "asesino" abandone la ejecución musical. En realidad es el contexto de violencia en la Argentina de los 70 el que pone punto final al cuarteto de cuerdas y a la carrera musical de Moyano, dando inicio al destierro. Para el narrador el recuerdo de esta historia significa también el fin de la escritura y los recuerdos que ésta evoca:

Entonces decidí, según recomendaba Hesíodo por temor a la navegación y a los naufragios, colgar la viola y el timón, y ahora mismo estos recuerdos, sobre el tranquilo humo del hogar. (161)

\section{III- Una subjetividad del extrañamiento y del desgarro}

En los dos relatos analizados observamos cómo se va configurando un lugar fluctuante y conflictivo de identificación. La situación fronteriza del emigradoexiliado-desterrado se construye a través de diversas imágenes, como la del equilibrista Manuel intentando superar la distancia que lo separa del objeto deseado en "María Violín" y la de un bicho prendido en la oreja de la pianista, apenas sostenido y suspendido en una condición inverosímil en "Un silencio de corchea". Allí el narrador proyecta su propia situación de músico incomprendido y de ser humano amenazado a la situación de ese bicho, que también como un equilibrista a punto de caer intenta denodadamente sostenerse.

En general, en todos los relatos que componen Un silencio de corchea se construyen los conflictos identitarios de un sujeto atravesado por los recuerdos y las fluctuaciones entre el allá /acá y el ayer/hoy. Las huellas de la enunciación desde la lejanía y la distancia se manifiestan claramente en las constantes referencias a "esas tierras", "esos tiempos" para hablar de la Argentina en la década del 70. 
Se configuran de esta manera figuras de una identidad cercenada y mutilada, de aquello que no pudo ser, que se vio repentina y violentamente clausurado. Esa es concretamente la situación del exiliado político que se textualiza en estos relatos. La experiencia de una identidad fracturada, de una memoria clausurada y del esfuerzo por reconstruir sus fragmentos dispersos.

Mientras en "María Violín" se narra el exilio en Madrid, en "Un silencio de corchea", por el contrario, se textualiza un clima pre-exilio, un sentimiento de no pertenencia y de destierro en el propio país por la condición de músico del narrador.

Esa condición de músico "clásico" y de habitante del "interior" del país constituye otras formas del exilio ${ }^{4}$. En los relatos que retoman las actuaciones musicales constantemente se recuerdan las condiciones "precarias" de ejecución, de infraestructura, de producción y el sentimiento de carencias: "a falta de salas..."; "éramos especies de músicos ambulantes, rurales, casi de a caballo" (13). Se trata de una música lejana, incomprensible, que generalmente no gusta al auditorio al que se destina y que se ejecuta en condiciones poco favorables. En esos "últimos rincones del Cono Sur del mundo" (13), estos músicos representaban la llamada "música culta", la presencia de la "lejanísima Europa". El sentimiento de distancia se presenta de esta manera como doble: en América, respecto de Europa y su música; y en España, respecto del "lejano Cono Sur" donde se encuentra su patria.

Esa sensación de estar "fuera de lugar" o en un lugar "extraño" se condensa a través de imágenes tales como las que se textualizan en "Los incorpóreos": "ese pato tan absurdo fuera del agua para siempre" (25), un "pato que había olvidado la gracia de los ríos" (28) y que finalmente se designa como un "pato exiliado" (29).

Sin embargo, en ambos espacios es precisamente esa música, producida en un tiempo lejano, la que le permite asumir un rol, un espacio propio de pertenencia y de vivencias y encontrar una posible forma de supervivencia. La falta de auditorio y de reconocimiento hacia la labor del músico, se suma a la sensación de no ser útil a la comunidad o de ser un estorbo que es previo al exilio. Esta es una actitud de desprecio que se destaca siempre como proveniente tanto de las esferas oficiales como del pueblo en general.

Esta atmósfera, que está presente en todos los relatos, cobra mayor fuerza en "Un silencio de corchea" a través de la analogía entre la situación del bicho, la del escritor antes de exiliarse y la del músico que se encuentra en un lugar donde no quieren su presencia. Esta analogía se manifiesta igualmente en las conclusiones a las que el narrador arriba sobre la condición existencial del bicho:

Lo que pesaba realmente de él, aparte de su realidad física, era el significado de la situación que había creado con su insólita circunstancia. Porque ser un bicho y es-

\footnotetext{
${ }^{4}$ Se trata de un "exilio interno" que ha sido constantemente observado por la crítica en la escritura de Moyano. Cfr. al respecto Gil Amate, 1993.
} 
tar prendido de la oreja de una pianista durante un concierto y en el Día Universal de la Música lo colocaba finalmente, en cuanto a su necesariedad o verisimilitud, en un terreno muy resbaladizo donde quizás no pudiera sostenerse mucho tiempo. (156)

Concluye entonces el narrador que "la situación del bicho carecía de congruencia ontológica".

El sentimiento de una identidad fracturada, a medio fraguar, la conciencia de sentirse extraño o fuera de lugar se repite a modo de hilo conductor o leit motiv confiriendo unidad y continuidad a todos los relatos. Esta situación fronteriza del emigrado que se construye a través de la figura del equilibrista se sintetiza a través del título de una sonata que Schubert escribe en 1824, Arpeggione, en homenaje a un instrumento musical antiguo, mezcla de violoncello y de guitarra, "que no pudo cuajar en instrumento y se extinguió". Los integrantes del cuarteto de cuerdas deciden llamar de ese modo a uno de sus más fieles oyentes, un perro al que bautizaron Arpeggione en homenaje a Schubert y a ese instrumento que no prosperó.

\section{BIBLIOGRAFÍA}

GIL AmATE, Virginia.

1993 Daniel Moyano: la búsqueda de una explicación. Oviedo: Departamento de Filología Española-Universidad de Oviedo.

GILIO, María Esther.

1986 "La música que brota de la tierra"(Entrevista a Daniel Moyano), en Conversaciones. Buenos Aires: Ediciones de La Flor, pp. 67-78.

LÓPEZ, Irene.

1998 "Las referencias musicales en El trino del diablo de Daniel Moyano", inédito.

RICOEUR, Paul.

1984 "La vida: un relato en busca de un narrador", en Educación y politica. Buenos Aires: Docencia, pp. 45-58.

ROWELL, Lewis.

1996 Introducción a la filosofía de la música. Barcelona: Gedisa. 